\title{
Segurança e soberania alimentar indígena no extremo Norte do Amapá - Brasil
}

\author{
Indigenous food security and sovereignty in the extreme north of Amapá - Brazil \\ Seguridad y soberanía alimentaria indígena en el extremo norte de Amapá - Brasil
}

Recebido: 30/03/2021 | Revisado: 10/04/2021 | Aceito: 14/04/2021 | Publicado: 28/04/2021

\author{
Claudiane de Menezes Ramos \\ ORCID: https://orcid.org/0000-0002-8837-5565 \\ Universidade Federal do Amazonas, Brasil \\ Universidade Federal do Amapá, Brasil \\ E-mail: claudiane@unifap.br \\ Hiroshi Noda \\ ORCID: https://orcid.org/0000-0001-8813-7586 \\ Universidade Federal do Amazonas, Brasil \\ E-mail: hnoda@inpa.gov.br \\ Ayrton Luiz Urizzi Martins \\ ORCID: https://orcid.org/0000-0002-9275-8745 \\ Universidade Federal do Amazonas, Brasil \\ E-mail: ayrton@ufam.edu.br
}

\begin{abstract}
Resumo
Os povos indígenas que habitam a Terra Indígena Uaçá, no extremo norte do estado do Amapá desenvolveram uma rede de relações complexas entre seres visíveis e invisíveis que operam para existência de um modo de vida integrado ao meio ambiente. Os Galibi-Marworno, Karipuna e Palikur-Arukwayene conseguem viver dentro da Terra Indígena Uaçá com as condições que ela lhes oferece, cultivando e manejando uma alta diversidade de espécies animais e vegetais, lançando mão de distintas práticas, distintos conhecimentos, em contínua transformação, um eterno recomeço de vida, o que vem garantindo a segurança e soberania alimentar. $\mathrm{O}$ artigo contempla um dos resultados da minha pesquisa de Doutorado que teve como objetivo principal compreender a importância do cultivo e manejo da agrobiodiversidade para segurança e soberania alimentar na Terra Indígena Uaçá. Adotei o Estudo de Caso como método de abordagem da pesquisa e técnicas interdisciplinares para levantamento das evidências de campo como, listagem livre, rodas de conversa, relatos orais, observação direta, observação participante e entrevistas semiestruturadas.
\end{abstract}

Palavras-chave: Agrobiodiversidade; Uaçá; Meio ambiente.

\begin{abstract}
The indigenous peoples who inhabit Uaçá, in Brazil's Northern Amapá state, have built a network of complex relationships between visible and invisible beings that bring about the existence of a way of life integrated with the environment. The Galibi-Marworno, Karipuna, and Palikur-Arukwayene indigenous peoples manage to live within the conditions that their territory offers them. They cultivate and manage a high diversity of animal and plant species, make use of different practices, different knowledge, all in a continuous transformation, an eternal new beginning for life, which has ensured their food security and sovereignty.This article examines one of the results of my $\mathrm{Ph} . \mathrm{D}$ research, which has as its main objective to understand the importance of cultivation and management of agrobiodiversity for food security and sovereignty in Uaçá Indigenous Land. I adopted the case study as a research approach method as well as interdisciplinary techniques for field evidence. During the field research, I gathered field notes, rounds of conversation, oral reports, direct observation, participant observation, and semi-structured interviews.
\end{abstract}

Keywords: Agrobiodiversity; Uaçá; Environment.

\section{Resumen}

Al norte de Brasil, los pueblos indígenas que habitan Uaçá, en el estado de Amapá, han construido una red de complejas relaciones entre seres visibles e invisibles que dan lugar a la existencia de una forma de vida integrada con el medio ambiente. Los pueblos indígenas Galibi-Marworno, Karipuna y Palikur-Arukwayene logran vivir con las condiciones que les ofrece su territorio. Cultivan y manejan una alta diversidad de especies animales y vegetales. Además, hacen uso de diferentes prácticas y conocimientos, todo en una transformación continua, en un eterno nuevo comienzo de vida, que ha asegurado su seguridad y soberanía alimentaria. Este artículo examina uno de los resultados de mi investigación de doctorado, que tiene como principal objetivo comprender la importancia del cultivo y manejo de la agrobiodiversidad para la seguridad y soberanía alimentaria en la Tierra Indígena Uaçá. Adopté el estudio de caso como un método de enfoque de investigación, así como técnicas interdisciplinarias para 
las evidencias de campo. Durante la investigación de campo realicé rondas de conversación, reuní notas de campo, informes orales, observación directa, observación participante y entrevistas semiestructuradas.

Palabras clave: Agrobiodiversidad; Uaçá; Medio ambiente.

\section{Introdução}

No Brasil, os conceitos Segurança e Soberania alimentar têm aplicação no âmbito das políticas públicas que visam "garantir e assegurar condições de alimentação e nutrição como um direito fundamental de todo ser humano" (Burity et al. 2010, p.12). O conceito de soberania alimentar defende que cada nação tem o direito de definir políticas que garantam a Segurança Alimentar e Nutricional de seus povos, incluindo aí o direito à preservação de práticas de produção e práticas alimentares tradicionais de cada cultura (Valente et al. 2016).

Maluf (2011) propõe que para alcançar a soberania alimentar é primordial que cada povo tenha acesso à terra, à água, às sementes nativas, e sobretudo, ao respeito e a valorização da cultura alimentar historicamente adotada dentro de cada grupo étnico. Nesse sentido, a soberania alimentar também pode ser pensada como uma forma de "resistência ao monopólio da produção e distribuição dos alimentos em nível global”, que são causas estruturais da fome no planeta (Hoyos \& D’Agostini, 2017).

O objetivo da indústria de alimentos é a padronização da alimentação mundial. Um exemplo explícito disso é que existem no mundo mais de 50.000 plantas comestíveis (Gruber, 2017), no entanto, segundo a Food and Agriculture Organization [FAO] (2018), a alimentação mundial baseia-se principalmente em 15 espécies, sendo as mais consumidas: o trigo, o arroz, e o milho, o que nos leva a constatação de que com uma dieta cada vez mais restrita, aliada à má distribuição dos alimentos, a fome mundial tende a aumentar.

Na Amazônia ${ }^{1}$ a alimentação está muito relacionada com a identidade dos povos que a habitam. Dácio (2017, p. 20) afirma que "a segurança alimentar na Amazônia é favorecida pela complexidade vivenciada nas práxis cotidianas de identidade societária e/ou consaguinidade". Proponho neste trabalho contribuir com a construção de um conceito sobre o que é segurança e soberania alimentar para os povos indígenas, sobretudo para os povos indígenas do norte do estado do Amapá - atualmente territorializados no município de Oiapoque - uma vez que a produção literária sobre o assunto é escassa.

\section{Metodologia}

A pesquisa de natureza qualitativa foi conduzida pelo método estudo de caso (Gil, 2008; Yin, 2015), que é caracterizado pelo estudo profundo, exaustivo, de um ou de poucos objetos, de maneira a permitir um conhecimento amplo e detalhado do caso (Gil, 2008). Este método permite o uso de várias fontes de evidencias e múltiplas técnicas de pesquisa (Noda et al. 2013). As principais fontes de evidências, para um estudo de caso, elencadas por Yin (2015), são: documentos, registros em arquivos, entrevistas, observação direta, observação participante e artefatos físicos.

Este artigo apresenta um dos resultados da minha tese de Doutorado que teve o objetivo geral compreender o processo de conservação da agrobiodiversidade e a sua contribuição para segurança e soberania alimentar dos povos indígenas do Oiapoque. Foi combinado o arcabouço teórico e metodológico da Etnobiologia e Etnoecologia (Posey, 1986; Toledo, 1992) com a teoria da complexidade (Morin, 1998; 2013). A Etnoecologia é uma ciência com abrangente entrecruzamento de saberes, que estuda a como as pessoas inserem-se culturalmente nos ecossistemas e interagem com os elementos que os compõe (Toledo, 1992).

A pesquisa de campo transcorreu na Terra Indígena (TI) Uaçá (Figura 1) nos anos de 2018, 2019 e 2020, após aprovação e autorização do CEP/CONEP (parecer n 3.167.107). A TI Uaçá está localizada no município do Oiapoque, estado

\footnotetext{
${ }^{1}$ Aqui me refiro ao contexto da Amazônia brasileira. Ela engloba os estados da Região Norte (Acre, Amazonas, Amapá, Pará, Rondônia, Roraima e Tocantins), Centro Oeste (Mato Grosso) e Nordeste (Maranhão), (Becker, 2005).
} 
do Amapá. Considerando as informações do último censo do Instituto Brasileiro de Geografia e Estatística [IBGE] (2010) Oiapoque é o segundo maior município em extensão territorial entre os 16 Municípios do estado do Amapá. Sua população em 2010 era de 20.509 pessoas e com uma estimativa em 2020 de 27.906 pessoas (IBGE, 2020). Oiapoque possui uma fronteira fluvial com a Guiana Francesa, delimitada principalmente pelo rio Oiapoque, A fronteira do Brasil com a Guiana Francesa tem $730,4 \mathrm{~km}$ de extensão, dos quais 427,2 km são por rios (Itamaraty, 2020).

Vivem na TI Uaçá aproximadamente oito mil indígenas pertencentes a três etnias: Karipuna, Palikur-Arukwayene e Galibi Marworno (DSEI, 2019). Os Karipuna são heterogêneos do ponto de vista étnico (Apio, 2009, p. 11). São falantes do khéuol $^{2}$ e do português. Em comunicação pessoal a liderança Karipuna, ex cacique L. dos Santos (2018), afirma que os Karipuna se formaram a partir de vários grupos indígenas e não indígenas, principalmente dos que fugiram dos processos violentos de colonização impostos pelos Europeus em outros estados, como o Pará e o Amazonas, e encontraram na região do Oiapoque uma área de refúgio.

Os Palikur-Arukwayene pertencem ao tronco linguístico Aruak, falam sua língua parikwaki e português. São habitantes originários da região (Apio, 2009, p.10). Schroeder et al. (2017, p. 2) afirmam que os Palikur-Arukwayene são os parentes vivos mais próximos dos Tainos, povos indígenas pré-colombianos que habitavam as Antilhas e Bahamas, com os quais Cristovão Colombo teve os primeiros contatos na América Central. Os Palikur-Arukwayene organizam-se em setes clãs: Kamuywene/Gente do Sol, Waxeyene/ Gente da Montanha, Kwakyeyene/ Gente do Ananás, Wayveyene/Gente da Lagarta, Kawokyene/Gente da Onça e Wakavunhene/Baptiste (informações de campo).

Os Galibi-Marworno são falantes do khéuol e do português. Essa etnia originou-se a partir da fusão interétnica dos povos indígenas Maraon e Aruã com os Saramaca, povo businenge $e^{3}$ da Guiana Francesa. Os Maraon são citados por viajantes na região do Oiapoque desde o século XVII e os Aruã são oriundos da ilha do Marajó, no Pará, que migraram no século XVIII em fuga das perseguições e explorações dos Portugueses (Santos, 2015, p. 29).

Figura 1. Localização geográfica da Terra indígena Uaçá.
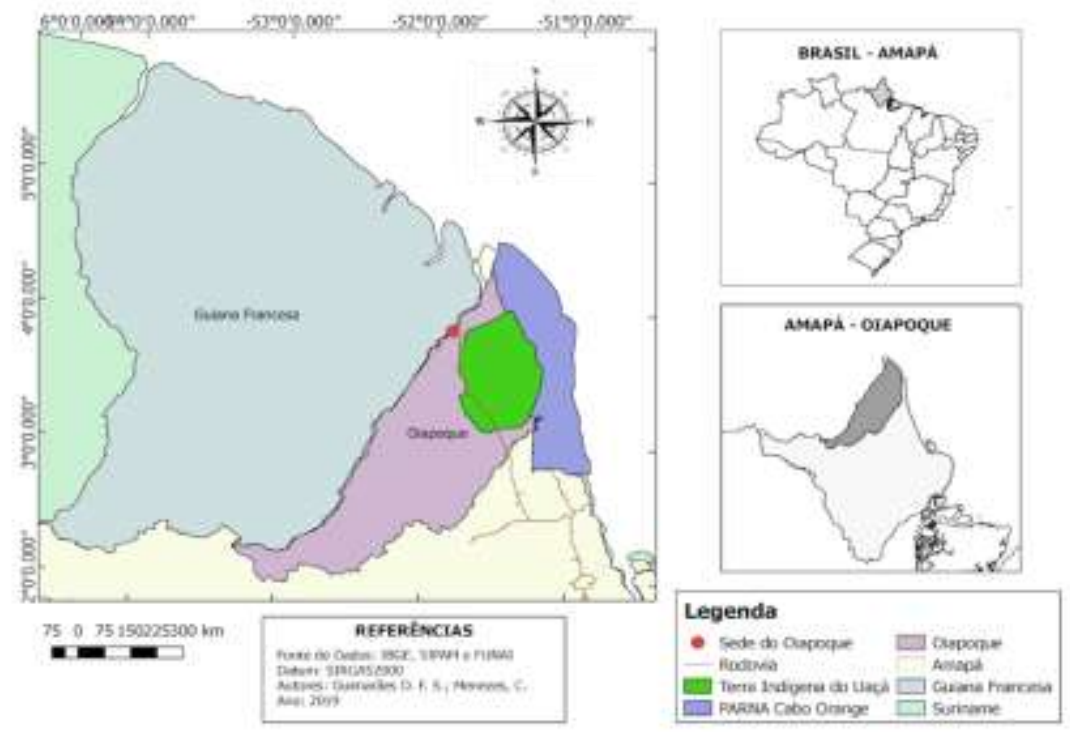

Fonte: Guimarães e Menezes (2019).

\footnotetext{
${ }^{2}$ Língua indígena variante do francês e do criolo falado na Guiana Francesa.

${ }^{3}$ São grupos cuja origem remonta escravos negros fugidos das plantations da Guiana Holandesa, atual Suriname (Informações de campo).
} 
$\mathrm{Na}$ coleta de dados foram utilizadas técnicas interdisciplinares de pesquisa: listagem livre, entrevistas semiestruturadas, relatos orais, história de vida, roda de conversa, observação direta e observação participante (Posey, 1986). Participaram diretamente por meio de entrevistas e acompanhamento nas roças 20 famílias e indiretamente através de observações, roda de conversa, mais de 200 famílias nas aldeias Kumarumã e Ikawakun. O roteiro de entrevistas incluía informações sobre os tipos de alimentos, a origem dos alimentos (local ou da cidade), quem é o responsável pela alimentação, quais são os ecossistemas utilizados para obtenção dos alimentos, e por fim, informações sobre mudanças na alimentação. Mas no decorrer das entrevistas surgiram novos elementos, principalmente relacionados a cosmologia local.

A análise dos dados foi sobretudo qualitativa. A transcrição das entrevistas foi por meio do software Elan (The Language Archive, 2019). Após a transcrição dos dados, criei uma estrutura descritiva para cada família em uma planilha da Microsoft excel. Posteriormente, realizei a análise de conteúdo (Bardin, 2006), técnica que possibilita a descrição do conteúdo manifesto e latente nas comunicações (Gil, 2008, p. 09).

$\mathrm{O}$ fato de eu ser indígena contribuiu para realização dessa pesquisa, na medida que tenho estabelecidas relações de proximidade e confiança com os povos indígenas da região do Oiapoque. Essas relações foram sendo estabelecidas a partir de 2016, ano em que tomei posse e passei atuar no ensino, pesquisa e extensão, como professora da Universidade Federal do Amapá, Campus Binacional de Oiapoque - AP.

\section{Resultados e Discussão}

\subsection{Segurança e Soberania Alimentar Indígena}

Em um debate sobre sistemas alimentares indígenas, M. Broggio (Informação verbal) ${ }^{4}$, que na ocasião representou a FAO, palestrou que na concepção dessa organização, uma pessoa tem segurança alimentar quando consome 2.000 kcal por dia, sacia a fome, ou se alimenta pelo menos três vezes ao dia. Desta forma, nota-se que este conceito é simplista, não contemplando questões etnopolíticas que poderiam tornar o conceito mais sofisticado, no sentido de contemplar diferentes formas de constituir o que é alimentação/nutrição adequada para diferentes populações humanas.

Para nós, povos indígenas, a segurança alimentar não é somente uma questão de quantidade de calorias, mas está relacionada a qualidade dos alimentos que constroem corpos fracos ou fortes, adequados ou inadequados para viver bem. Para obtenção de alimentação que consideramos adequada, dependemos principalmente da segurança sobre o território que ocupamos, a terra demarcada e protegida, sem invasões, para que o cultivo e o manejo da agrobiodiversidade seja feito por nós, nos rios, lagos e florestas, com ou sem a ajuda e a troca de conhecimentos com povos vizinhos, como sempre fizemos.

A segurança e a soberania sobre o território é um desafio que percorre toda a história indígena na região do Baixo Oiapoque (Batista, 2020), mas no Brasil podemos generalizar dizendo que as Terras Indígenas estão cada vez mais pressionadas pelas atividades econômicas, principalmente de caráter agropastoril e minerador. Fora da Amazônia as terras indígenas são bastante reduzidas, acarretando dificuldades para a reprodução econômica, ambiental, física e cultural de seus habitantes (Santos et al. 2007, p. 42), isso é importante para pensar em políticas de segurança e alternativas de soberania alimentar para povos indígenas, que não mais detêm a integridade de seu território.

Os deslocamentos compulsórios, migrações e redução contínua dos territórios ancestrais propõem a necessidade de pensar diferentes estratégias de segurança alimentar/nutricional para diferentes povos indígenas, visto que sofrem de diferentes níveis de colonialismo e esbulho de seus territórios. Em muitas terras indígenas simplesmente não há mais como caçar ou pescar. Em outras, até a agricultura tornou-se difícil, porque há tão pouco território disponível, que não é possível permitir que

\footnotetext{
${ }^{4}$ No $3^{\circ}$ Congresso Internacional dos Povos Indígenas - CIPIAL, em Brasília, 03 a 05 de julho de 2019.
} 
a terra descanse o tempo necessário para que se torne novamente produtiva, como acontece com os Guaraní, em Mato Grosso do Sul (Leite, 2007a).

Cada povo indígena tem sua especificidade territorial que incorre no acesso aos recursos naturais para garantir a segurança alimentar, sem território e sem acesso aos recursos nele existentes, não há segurança nem soberania alimentar. Para garantirmos a soberania alimentar indígena é necessária a autonomia, o direito de escolher o que produzir, quando produzir, quanto produzir, mediante a necessidade demográfica de cada comunidade.

Independente dos níveis de patrilinearidade praticada no interior de diferentes culturas indígenas, as mulheres têm um papel estruturante no estabelecimento de proteção aos cultivos tradicionais, planos de manejo de caça e de pesca, bem como a utilização de saberes tradicionais referentes a fertilidade do solo, que permitem que a agricultura indígena dispense o uso de agrotóxicos e outras tecnologias industriais desenvolvidas para a produção de alimentos. Dentre os povos indígenas, a proteção e o desenvolvimento da agrobiodiversidade está diretamente relacionada ao recorte de gênero, e portanto, ao papel das mulheres na manutenção de desenvolvimento da sabedoria alimentar.

A segurança e a soberania alimentar dos povos indígenas no Brasil correm riscos em todos os sentidos. Além do esbulho territorial, o desmatamento no entorno e também no interior das terras indígenas se constituem como o maior risco para a segurança alimentar dos povos etnicamente diferenciados da Amazônia. Em 2019, o aumento do desmatamento na Amazônia foi de 34,41\%, mas nas Terras Indígenas, esse aumento foi de $80 \%$ (Oviedo et al. 2020).

As 23 Terras Indígenas que concentram 90\% do desmatamento estão na Amazônia (Oviedo et al. 2020). Os povos indígenas que vivem nessas TI estão em situação de vulnerabilidade alimentar, perderam suas áreas de coleta, de caça, de cultivo, além de terem seus rios e solos contaminados. A consequência imediata desse processo de degradação por meio do desmate é a fome entre povos indígenas, muitos com a dieta restrita a alimentos industrializados por terem perdido sua condição de produtores de alimentos.

Na TI Uaçá, a invasão para o desmatamento ainda é muito pontual, graças a fiscalização autônoma e a capacidade de mobilização política dos povos indígenas que vivem nessa região. Segundo M. A. Silva (2020), a vigilância e a fiscalização são práticas ativas nas Terras Indígenas do Oiapoque desde o período do reconhecimento, demarcação e homologação, como forma de demonstrar a preocupação e interesse pelo território que iniciou seu processo de demarcação ainda na década de 1970 .

Falar de alimentação indígena em um país de dimensões continentais como o Brasil requer um criterioso cuidado, para não cairmos em generalizações (Salgado, 2007). Na TI Uaçá a alimentação é baseada em um domínio e manejo de uma rica agrobiodiversidade, ancorada em uma complexidade sistêmica que inclui a sazonalidade ${ }^{5}$, a observação das constelações e dos ciclos lunares.

A diversidade alimentar na TI Uaçá está relacionada a capacidade de manejar uma diversidade de ecossistemas concomitantemente. Em alguns alimentos foram incorporados os saberes e os sabores de outras culturas, como a Francesa, decorrente de "um sistema interétnico regional que integra as etnias que se movimentam estabelecendo alianças econômicas, religiosas, redes de parentesco e trocas culturais nos territórios francês e brasileiro" (Musolino, 2006, p.110), sem dúvida ainda persiste nos dias atuais. Um exemplo de troca cultural entre o território francês é a caramelização do açúcar como base de guisados de carnes de caças, corroborando com Suremain e Katz (2009), que a "alimentação encarna e cristaliza diferenças culturais e sociais, sem deixar de considerar a trajetória histórica dessas sociedades".

Uma adaptação bem sucedida às condições ambientais, aliada à fartura dos ecossistemas tropicais, pode ter sido fator decisivo para o estabelecimento de culturas na Amazônia (Salgado, 2007). Na TI Uaçá, os ecossistemas manejados para garantia da segurança e soberania alimentar são: campos alagados, florestas de terra firme, lagos e montanhas, sobre os quais

${ }^{5}$ Variações na produção e consumo de alimentos, de acordo com a estação do ano (Leite, 2007a). 
os três povos que a habitam apresentam um grande domínio e conhecimentos sobre os ecossistemas que vem permitindo uma sobrevivência digna, com sustentabilidade.

\subsection{Diversidade alimentar e sua importância na segurança e soberania alimentar local}

A região do baixo Rio Oiapoque apresenta uma alta riqueza biológica, em virtude da diversidade de biomas - mangue, campos alagados, florestas de terra firme, florestas alagadas, cerrado, hidrografia (Barros et al. 2013). A diversidade aquática chama a atenção em termo de biodiversidade, os pesquisadores indígenas do Museu Kuahí et al. (2018), identificaram 164 espécies nas TI do Oiapoque (Galibi, Juminã \& Uaçá). Nesta pesquisa levantei cerca de 60 espécies de animais importantes na alimentação na TI Uaçá.

Um ecossistema que favorece a diversidade alimentar na TI Uaça é denominado campos alagados, corresponde a 37,6 \% do território indígena com 194.898 ha (Barros et al. 2013), bastante significativo em função das maiores e mais populosas aldeias, Kumenê e Kuamarumã (Figura 2) se localizarem em ilhas nos campos alagados. Os campos alagados são importantíssimos para segurança e soberania alimentar local, principalmente na época do verão/seca, com a maior disponibilidade de peixes e aves.

Figura 2. Vista aérea dos campos alagados, Aldeia Kumarumã.

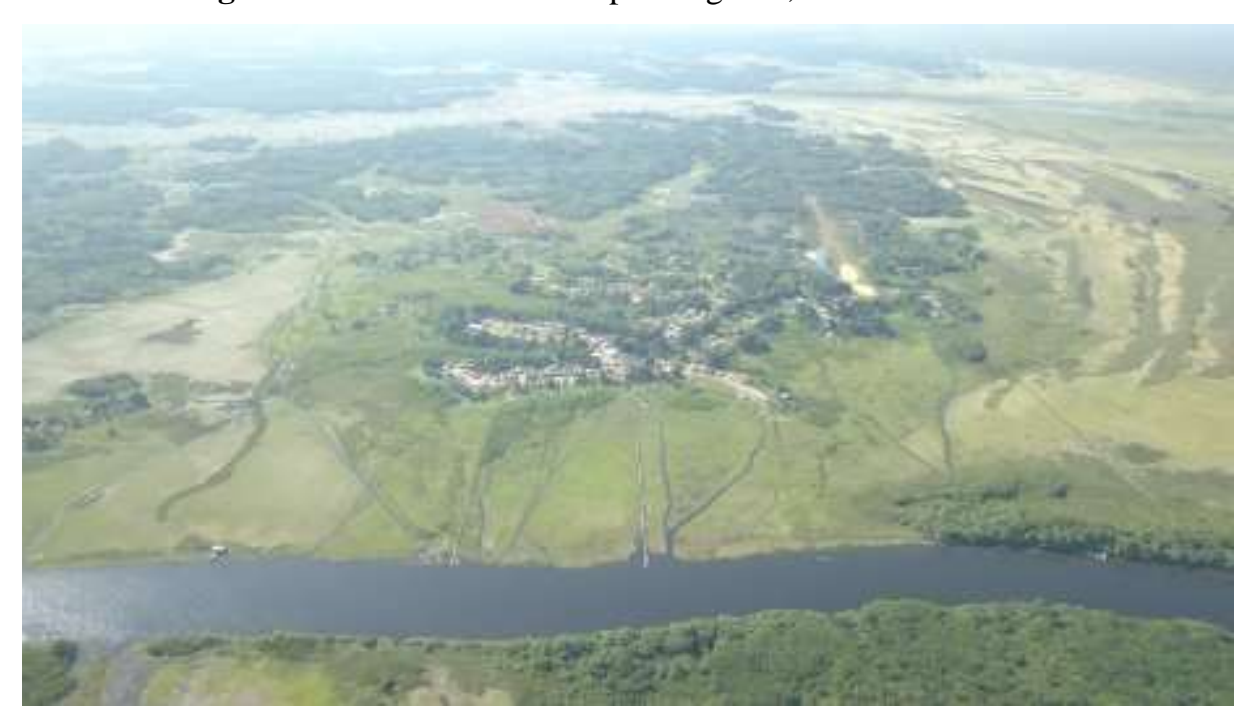

Fonte: O. Gislael (2019).

Fazendo um paralelo com os "homens anfíbios" de Fraxe (2011), onde a relação homem/natureza dos habitantes das várzeas amazônicas ocorrem de forma simbiôntica, constituindo um espaço único, onde os camponeses moram e trabalham produzindo e reproduzindo material e simbolicamente suas vidas, tendo a água como principal vetor dessas relações, os povos indígenas do Uaçá também desenvolveram estratégias de sobrevivência em um ambiente em que a água (dos rios, do oceano, das chuvas) mediam as relações com os seres vivos visíveis e seres invisíveis (karuanas) ${ }^{6}$.

Vale salientar que a sazonalidade entre os povos indígenas do Oiapoque não é fixa, constante, e sim dinâmica com forte vinculação às constelações, aos animais e as plantas e aos seres invisíveis (Karuanas). Não podemos definir com clareza o inverno e o verão, o que podemos definir é que o inverno é o período chuvoso que inicia ora em novembro, ora em dezembro, com o alagamento dos campos e o verão é quando os campos alagados começam a secar, ora final de maio, ora em junho.

\footnotetext{
${ }^{6}$ São pessoas que vivem em outro mundo, onde são gente como nós, e que apenas os pajés conseguem ver e se comunicar com eles (Iepe, 2009).
} 
Os povos indígenas do Oiapoque, sobretudo os Palikur-Arukwayene possuem uma astronomia sofisticada que orientam/mediam as interrelacões entre os seres vivos. Para Green e Green (2010), os Palikur-Arukwayene não só dominam e conhecem as formas das constelações, mas também conhecem diferentes qualidades de seu movimento em diferentes períodos do ano. A época que coincide com os solstícios na astronomia ocidental, junho e dezembro, são os meses de maior fartura de alimentos, início do período seco e chuvoso, respectivamente.

A explicação para fartura de alimentos nesses períodos está na astronomia indígena dos povos do Uaçá, e as chuvas são as principais responsáveis. Quem traz as chuvas são as constelações, a fartura do período seco está ligada a constelação Kusuvwí, para a etnia Palikur-Arukwayene e La pusiê para as etnias Galibi-marworno e Karipuna. Essa constelação na astronomia ocidental é identificada como as plêiades e fica visível ao amanhecer de abril a maio originando a abundância nos meses posteriores, muita fartura de peixes e aves, pois as águas baixam, os campos secam e os peixes se concentram nos rios, facilitando a pesca (observações em campo).

O movimento das estrelas é entendido como uma viagem que se dá em torno deste mundo, passando pelo fundo, para ressurgir no céu da manhã (Green \& Green, 2010). Os povos do Uaçá afirmam que quando as constelações ficam invisíveis no céu é porque elas estão passando por debaixo da água. S. dos Santos (Comunicação pessoal), da etnia Galibi-Marworno disse que "quando la pusiê está passando por debaixo da água ela leva os karuanas para trazer a força, a energia para os animais, para as plantas, principalmente para a mandioca, ela volta no ano que vem renovada, com todo material escolar dela".

O início do período chuvoso, em dezembro, também é caracterizado por uma fartura de alimentos, esse período coincide com o solstício de inverno, quando os peixes sobem os rios, entram nos campos com as primeiras chuvas. Kayeb para etnia Palikur-Arukwayene é a constelação relacionada às primeiras chuvas, visível ao amanhecer nos meses de dezembro a início de fevereiro. De acordo com o sábio Wetmin, "A primeira chuva é para fazer entrar nos campos os peixes que vivem nas margens dos rios. Por isso que o Kayeb é o que faz estes peixes entrarem. Ele faz entrar o tamuatá, o tamuatá preto e os acarás” (Pesquisadores indígenas do Museu Kuahí et al. 2018).

Kayeb na cosmologia Palikur-Arukwayene é uma anaconda multicéfala, cujo corpo abrange as estrelas consteladas alhures como Escorpião, o Cruzeiro do Sul e suas guardas e a matéria escura da via láctea (L. Green \& D. Green, 2010). Os Palikur-Arukwayene representam as constelações em esculturas em madeira. L. Green e D. Green (2010) afirmam que para os Palikur-Arukwayene as constelações são seres vivos, cujas vidas são representadas em esculturas de madeira. Corroborando o multiculturalismo dos povos indígenas proposto por Viveiros de Castro (2002), em que vivemos em um único mundo com diferentes formas de vida, de existências.

A constelação mais importante na vida dos indígenas do Uaçá é o KusuvwílLa pusiê (abr, Mai), além de mais importante é descrita por unanimidade entre as etnias locais, pois elas são responsáveis pela fartura de alimentos, contribuindo para segurança e soberania alimentar. Demonstrando assim, que as constelações não são objetos estáticos, mas sujeitos dinâmicos e dotados de agência, em constante interações/relações com os povos indígenas locais. Note-se que as constelações também fazem parte dos ciclos anuais dos povos indígenas no rio Tiquié, alto Rio Negro (ISA, 2020), corroborando com a afirmação de L. Green e D. Green (2010), que as constelações constituem a espinha dorsal do saber ecossistêmico, uma vez que orientam as práticas agrícolas, de caça, de coleta, de pesca, de construção, a vida em geral.

As constelações citadas nesta pesquisa são estrelas matutinas, ou seja, "nascem" antes do sol, nesse sentido, L. Green e D. Green (2010), interpretaram que o sol serve de guia para localizar as constelações sazonais ao longo do dia, permitindo rastrear o caminho das estrelas que nasceram logo ao amanhecer. A Via Láctea - aglomerados de planetas, estrelas e buracos negros em forma de espiral (Oliveira Filho \& Saraiva, 2004), é considerada pelos Palikur-Arukwayene como o rio celestial, rio do mundo, por onde o sol se movimenta. Essa teoria indígena vai de encontro com a pesquisa científica de Johansen et al. (2021), na qual estão considerando que a água pode fazer parte da formação de todos os planetas da Via Láctea. 
A lua também é um importante marcador para alimentação e movimentação na TI Uaçá. Na lua cheia são cultivadas nas roças algumas espécies comestíveis como banana, cará, abacaxi, batata-doce e cana de açúcar. A partir da observação dos movimentos da lua, se planejam para sair das aldeias com destino ao Oiapoque. Preferem sair na época da lua cheia, quando ocorre a maré mais alta. Saem das aldeias em barcos de madeira ou de alumínio (voadeira) na vazante da maré e esperam a subida da próxima maré na ponta do mosquito, foz do rio Oiapoque, para subir junto até a sede do município.

A maior influência da maré é no período seco/verão, em que os principais rios na TI Uaçá (Urukauá, Curipi e Uaçá) estão com o volume de água reduzido e a entrada da água salobra com a subida da maré provoca a mortalidade de peixes mais sensíveis ao sal, como o pacú (informação de campo). No verão a água dos rios apresentam muito sedimentos, com a coloração barrenta e a dos poços artesianos nas aldeias fica salobra. No período chuvoso, a cheia e a vazante da maré não modificam tanto a qualidade da água, os rios permanecem claro ou esverdeado.

A partir do mês de março, a chuva vai aumentando progressivamente os campos vão ficando submersos e os peixes, jacarés, tartarugas vão ficando mais dispersos dificultando a captura, nesse período aumenta o consumo alimentos industrializados e carne de caça. Os animais são caçados em floresta de terra firme, 53,3\% da TI e no cerrado, $1 \%$ da TI (Barros et al. 2013), o cerrado corresponde a pequenas áreas de transição entre campos alagados e floresta de terra firme.

A alimentação na TI Uaçá é composta por uma diversidade de alimentos naturais encontrados na própria terra indígena ou no entorno - peixes, mamíferos, aves, répteis, crustáceos, plantas cultivadas e manejadas/coletadas na floresta (Tabela 1), e complementada com alimentos industrializados comprados em Oiapoque. Foi verificado em campo, que em maio, quando as chuvas estão mais intensas e o rio atinge o nível máximo, o consumo de peixes e carnes de caça é diminui, pois não conseguem caçar e pescar devido a chuva, aumentando assim o consumo de alimentos industrializados, principalmente enlatados, ovos, calabresa, charque, mortadela e frango.

As mudanças sazonais e as regras locais de uso da biodiversidade provocam o uso de nichos diferenciados para obtenção de alimentos. As regras locais são impostas ao consumo de algumas espécies consideradas vulneráveis devido ao alto consumo, são elas, o pirarucu e o tracajá. A captura desses animais é proibida no momento de reprodução, de julho a dezembro para tracajá e de janeiro a maio para pirarucu.

As regras também são impostas a pesca de tucunaré fêmea no período da reprodução, quando estão "ovadas" de dezembro a fevereiro, não podendo ser capturadas. Também é proibido matar as aves de maio a agosto quando estão em seus ninhais, se reproduzindo. Essas regras tem funcionado bem, e são uma forma de garantir a segurança e soberania alimentar atual e futura. Quem desobedece às regras é submetido a trabalhos comunitários, como limpar a aldeia, se for reincidente, as lideranças indígenas impões punições mais severas.

Tabela 1. Diversidade alimentar na TI Uaçá.

\begin{tabular}{lll}
\hline & \multicolumn{2}{c}{ Mamíferos } \\
Nome comum & Nome científico & Onde encontra \\
\hline Anta & Tapirus terrestres & floresta \\
Caititu & Pecari tajacu & floresta \\
Capivara & Hydrochoerus hydrochaeris & floresta, campos alagados, \\
& & cerrado \\
Cuamba & Ateles marginatus & floresta \\
Cutia & Dasyprocta aguti & floresta \\
Guariba & Alouatta guariba & floresta \\
Paca & Cuniculus paca & floresta
\end{tabular}




\begin{tabular}{|c|c|c|}
\hline Queixada & Tayassu pecari & $\begin{array}{l}\text { floresta, cerrado, campos } \\
\text { alagados }\end{array}$ \\
\hline Tamanduá & Myrmecophaga tridactyla & floresta \\
\hline Veado vermelho & Mazama sp. & $\begin{array}{l}\text { floresta, cerrado, campos } \\
\text { alagados }\end{array}$ \\
\hline Veado branco & Odocoileus virginianus & $\begin{array}{l}\text { floresta, cerrado, campos } \\
\text { alagados }\end{array}$ \\
\hline Tatu & Dasypodidae & floresta \\
\hline
\end{tabular}

\section{Aves}

Nome comum
Arapapá
Carará
Cauauá
Galinha caipira
Garça
Inambu
Jaburu
Jacamim
Jacupéu
Maguari
Mutum
Pato selvagem
(marrequinha)
Tucano

Tucano

\section{Nome comum}

Acará

Anujá

Apahari

Aracu

Aruanã

Bagre

Carangueijo

Dãxẽ

Filhote

Jeju

Jundiá

Matupiri

Pescada

Pintado

Piramutaba

Piranha

Pirarucu

\section{Nome científico}

Cochlearius cochlearius

Anhinga anhinga

Ciconiidae

Gallus gallus

Ardea alba

Crypturellus cinereus

Jabiru mycteria

Psophia crepitans

Penelope sp.

Ciconia maguari

Pauxi tuberosa

Nannopterum brasilianus

Ramphastidae

\section{Peixes e crustáceo}

\section{Nome científico}

Astronotus spp.

Trachelyopterus galeatus

Astronotus Ocellatus

Leporinus sp.

Osteoglossum bicirrhosum

Pimelodus spp.

Ucides cordatus

Acestrorrynchus spp

Brachyplatystoma filamentosum

Hoplerythrinus sp.

Rhamdia quelen

Astyanax fasciatus

Cynoscion sp.

Pseudoplatystoma corruscans

Branchyplatystoma vaillant

Pygocentrus sp.

Arapaima gigas

\section{Onde encontra}

campos alagados

campos alagados

campos alagados

quintal

campos alagados

floresta

campos alagados

floresta

floresta

campos alagados

floresta

campos alagados

floresta

\section{Onde encontra}

rio, lagos, igarapés rio, lagos, igarapés rio, lagos, igarapés rio, lagos, igarapés rio, lagos, igarapés rio, lagos, igarapés manguezal rio, lagos, igarapés rio próximo ao manguezal rio, campos alagados rio, lagos, igarapés rio, lagos, igarapés rio rio rio rio, campos alagados, lagos rio, lagos 


$\begin{array}{lll}\text { Surubim } & \text { Pseudoplatystoma } s p . & \text { rio } \\ \text { Tamatá } & \text { Hoplosternum sp. } & \text { rio, campos alagados } \\ \text { Topoio } & \text { não identificado } & \text { rio } \\ \text { Traíra açu } & \text { Hoplias } s p . & \text { rio, campos alagados, lagos } \\ \text { Traíra pongó } & \text { Hoplias } s p . & \text { rio, campos alagados, lagos } \\ \text { Tucunaré } & \text { Cichla } s p . & \text { rio }\end{array}$

\section{Répteis}

\section{Nome comum}

Cabeçudo

Camaleão

Jabuti carumbé

Jacaré-açu

Jacaré-coroa

Jacare-pedra (una)

Jacaré-tinga

Matamatá

Tracajá

\section{Nome comum}

Abacate

Abacaxi

Açai

Bacaba

Banana amapá

Banana branca

Banana grande

Banana prata

Banana violeta

Batata-doce

Camapu

Cana-de-açúcar

Cará

Coco

Cupuaçu

Daxina

Gengibre

goiaba

Inajá

Ingá

Jambo

Laranja

Limão

Macaxeira

\section{Nome científico}

Peltocephalus dumerilianus

Iguana iguana

Chelonoidis carbonaria

Melanosuchus niger

Paleosuchus trigonatus

Paleosuchus palpebrosus

Caiman crocodilos

Chelus fimbriatus

Podocnemis unifilis

\section{Onde encontra}

rio, campos alagados

floresta

floresta

rio, campos alagados

rio, campos alagados

igarapés, montanhas

rio, campos alagados

rio, campos alagados

rio, campos alagados

Agrobiodiversidade Vegetal

\section{Nome científico}

Persea americana

Ananas comosus

Euterpe oleracea

Oenocarpus bacaba

Musa ssp.

Musa ssp.

Musa ssp.

Musa ssp.

Musa ssp.

Ipomoea batatas

Physalis angulata

Saccharum officinarum

Dioscorea

Cocos nucifera

Theobroma grandiflorum

Colocasia esculenta

Zingiber officinale

Psidium guajava

Attalea maripa

Inga edulis

Syzygium jambolum

Citrus sp.

Citrus sp.

Manihot esculenta

\section{Parte comestível}

fruto

fruto

fruto

fruto

fruto

fruto

fruto

fruto

fruto

raiz

fruto

caule

raiz

fruto

fruto

raiz

raiz

fruto

fruto

fruto

fruto

fruto

fruto

raiz

\section{Onde encontra}

quintal

roça

floresta, quintal

floresta, quintal

roça

roça

roça

roça

roça

roça

roça

roça, quintal

roça

quintal

quintal

roça

roça, quintal

quintal

floresta, capoeira

quintal

quintal

quintal

quintal

roça 


\begin{tabular}{llll} 
Mamao & Carica papaya & fruto & quintal \\
Mandioca & Manihot esculenta & raiz & roça \\
Manga & Mangifera indica & fruto & quintal \\
Maracujá do mato & Passiflora cincinnata & fruto & roça \\
Pequi & Caryocar brasiliense & fruto & floresta \\
Pimenta & Capsicum sp & fruto & roça, quintal \\
Pupunha & Bactris gasipaes & fruto & capoeira, quintal \\
Tangerina & Citrus sp. & fruto & quintal \\
Taperebá & Spondias mombin & fruto & quintal \\
Tucumã & Astrocaryum aculeatum & fruto & capoeira, quintal \\
Urucum & Bixa orellana & fruto & quintal \\
\hline
\end{tabular}

Fonte: Trabalho de campo $(2018,2019,2020)$.

Na TI Uaçá os alimentos oriundos da caça e da pesca são consumidos preferencialmente cozidos ou assados. São raras as vezes que fritam algum alimento, quando fritam, geralmente, são alimentos exógenos como calabresa, mortadela. O consumo de animais domésticos é bastante limitado, uma vez que poucas famílias criam galinha, porco, boi, etc. Geralmente, a carne bovina é consumida em assembleias comunitárias. As lideranças indígenas envolvidas na organização da assembleia compram de um a três bois, nas pequenas fazendas do município de Oiapoque, dependendo da quantidade de participantes da assembleia.

Por outro lado, as carnes de caças são muito apreciadas, conforme a tabela acima, levantei 12 espécies de mamíferos que são importantes na alimentação. Analisando a alimentação de nove povos indígenas e ribeirinhos na Amazônia brasileira, peruana, boliviana e equatoriana, Dufour et al. (2016), indicam que o peixe é a principal fonte de proteína entre eles, no entanto, a caça é um alimento importantíssimo na dieta dos povos amazônicos.

A partir das informações de campo identifiquei que na TI Uaçá, as carnes de caça são classificadas de acordo com as preferências, que vai de carne de primeira para as mais preferidas e carne de quarta para as menos preferidas. As carnes de caça de primeira são: queixada, cutia, paca, caititu e tatu. Carnes de segunda: anta, capivara, tamanduá, macacos (guariba, cuamba, macaquinho). Carnes de terceira se referem as aves selvagens, na TI Uaçá são consumidas 12 espécies (Tabela 1). Por fim, as carnes de quarta são as carnes de animais domésticos como pato e galinha. Outras etnias também tem suas preferências como aponta Salgado (2007, p. 176):

A preferência por animais varia bastante; os Panará, por exemplo, são exímios caçadores de antas, os Kayabi preferem a carne de queixada e de macaco prego, os Asheninka gostam mais das aves. Os povos do Alto Xingu comem preferencialmente peixes, mas eventualmente comem algum animal de pena, evitando comer animais de pelo, que acreditam ser reencarnações de seus próprios espíritos. Os Shanenawá preferem caçar veado, vindo em seguida a paca e o tatu (Salgado, 2007, p.176).

Salienta-se que na TI Uaçá, a caça é uma atividade executada pelos homens, com auxílio de espingardas, e em alguns casos as flechas. Também é comum utilizar o cachorro, "muito útil na localização da caça ao farejar e rastrear animais de vários portes" (Labontê, 2018). Entre os Palikur-Arukwayene o preparo do pewru (cachorro) para a caça envolve uma complexidade de agentes envolvidos. É preparada uma pasta com substâncias animais e vegetais e passada nas pernas e focinho do cachorro às sextas-feiras, o tornando apto para a caça, mais forte, mais rápido e mais bravo. Labontê (2018, p. 20), descreve o preparo do pewru por seu povo da seguinte forma:

Para boa preparação do pewru é preciso buscar muitas coisas para fazer a pasta como o bico do pássaro mergulhão, a cabeça do urubu branco, a pele do pé da cutia, a pele do pé da paca, o nariz do veado, a pimenta vermelha o inseto 
wahbik, a formiga kasuksaniye. Cada componente da pasta é responsável em transferir uma habilidade ao pewru. Por exemplo, o bico do mergulhão transfere a força da mordida, a cabeça do urubu transfere o faro aguçado, o pé da cutia a rapidez (Labontê, 2018, p.20, reescrito).

É interessante notar na descrição do Labontê (2018), a relação íntima do pewru (Cachorro) com os caçadores e como ocorre uma interação ecológica entre diferentes seres (aves, mamíferos, plantas) que transmitem as suas propriedades para tornar o cão mais competente para caça. Cada ser exemplificado transfere a sua substância ao cachorro através da pasta. O bico do mergulhão o ensina a morder com força, a cabeça do urubu branco e o nariz do veado transferem o faro aguçado, o pé da cutia a esperteza e a rapidez, a formiga a coragem e o inseto wahbik a habilidade de entrar em buracos. Demonstrando assim que no mundo indígena tudo é uma continuidade e o fluxo entre os seres é ininterrupto.

Os melhores meses para caçar na TI Uaçá são de janeiro a março, pois nesse período há muita fruta madura (bacaba, açaí, tucumã, inajá, andiroba), os animais saem para se alimentar e são abatidos, geralmente próximos de igarapés. Os melhores horários de caça é bem cedo, meio dia e no final da tarde, horário que os animais se alimentam. A melhor época de caçar é na lua nova, pois a floresta fica mais iluminada, os animais se movimentam mais e fica mais fácil de encontrar os animais. Os animais caçados que andam só na mata são: paca, anta e veado, e os animais que sempre andam em bando nas florestas e nos campos são: macacos, capivara, caititu e queixada.

Em relação a pesca levantei que são consumidas 22 espécies de peixes (Tabela 1) que também são subdivididos de acordo com a preferência, os peixes de primeira: tucunaré, surubim, pescada, traira açú, aruanã e pirarucu. Os peixes de segunda: piranha, acará, dãxẽ, traíra pongó, tamatá, aracú e jeju. Quanto aos répteis, os quelônios mais consumidos são o tracajá e o cabeçudo, em seguida o matamatá e o jabuti. O camaleão também é muito apreciado, o jacaré-tinga é o mais preferido e consumido, o que tem gerado uma preocupação pois está espécie está cada vez mais difícil de ser encontrada. E o menos preferido é o jacaré-açu, também chamado de jacaré-cachorro, "devido a sua carne ser considerada imunda por alguns grupos familiares, em função do pitxiú/mau-cheiro" (Batista, 2020).

O caranguejo é uma espécie de crustáceo, que contribui para a segurança e soberania alimentar local, principalmente entre os Palikur-Arukwayene. Os caranguejos são capturados próximo a ponta do mosquito no Parque Nacional Cabo Orange (PNCO), parcialmente sobreposto a TI Uaçá, uma fronteira movediça em função do crescente depósito de sedimentos realizados pela dinâmica das marés. Este manguezal é formado a partir do encontro do Rio Oiapoque e seus afluentes com o oceano atlântico, na divisa com a Guiana Francesa (ICMBio, 2018). Batista (2020), afirma que aparentemente não há conflitos entre os gestores do Parque e os indígenas que capturam o caranguejo para compor sua dieta alimentar.

Segundo os pesquisadores indígenas do Museu Kuahí et al. (2018), os caranguejos são totalmente dependentes da lua e da maré, na lua cheia a maré cresce mais, e eles saem e andam, à noite saem para se alimentar. A captura ocorre na lua cheia, nos meses de julho e agosto, pois "nesse período os caranguejos saem para dançar, essas práticas acontecem desde muitos anos atrás até os dias de hoje”. (Pesquisadores indígenas do Museu Kuahí et al. 2018, p.111)

O fato de os caranguejos saírem para "dançar" dialoga com o perspectivismo ameríndio de Viveiros de Castro (2002) onde todos somos considerados sujeitos, o que muda é a natureza dos corpos. Demonstrando assim, que no pensamento indígena do Uaçá, os conceitos de natureza e cultura são posicionados diferentemente do pensamento ocidental, em que há uma divisão entre natureza e cultura. Após a "festa", os caranguejos retornam ao buraco nos mangues para se "recuperar", e no ano seguinte dançarem novamente. Além de consumir a carne do caranguejo, o casco também é utilizado na medicina tradicional.

Algumas regras que orientam o consumo na TI Uaçá como não capturar caranguejo ovado e outros animais no período de reprodução, reforça as teorias indígenas que orientam o uso dos recursos da biodiversidade, de que estes são finitos, e se não forem utilizados com sustentabilidade, poderão acabar. Silva (2020), salienta que de maneira geral, os povos indígenas 
usam os recursos a partir de uma racionalidade, com a consciência coletiva de atender uma necessidade social, como se alimentar. Desta forma, não podemos ser considerados "extrativistas" pois não apenas extraímos os recursos, somos coletores e semeadores de vida da Amazônia.

Em relação a agrobiodiversidade vegetal são cultivadas e manejadas para alimentação aproximadamente 36 espécies (Tabela 1), muito semelhantes aos dados da pesquisa de Dufour et al. (2016), onde levantaram 40 espécies de plantas alimentícias importantes na dieta dos povos amazônicos. Na TI Uaçá essas espécies são cultivadas em roças, quintais ou manejadas na floresta. A espécie mais cultivada nas roças é a mandioca, apresentando uma alta diversidade intraespecífica, são ao todo 40 variedades (pesquisa de campo).

O cultivo e o manejo da agrobiodiversidade tem sustentado e garantido a segurança e soberania alimentar na TI Uaçá. O sistema agrícola na TI Uaçá difere de um sistema agrícola capitalista pois é sustentado com uma alta biodiversidade, mantém a floresta em pé, não usa produtos químicos, além de respeitar os ciclos naturais. Esse tipo de sistema agrícola documenta uma estratégia agrícola indígena exitosa e representa um tributo a criatividade baseado nos conhecimentos indígenas (Altieri \& Nicholls, 2016).

A mandioca juntamente com o peixe são os alimentos mais consumidos na TI Uaçá, da mesma forma que em outros lugares da Amazônia (Adams et al. 2005; Chernela, 1989; Dufour et al. 2016; Murrieta et al. 2008; Salgado, 2007). Os estudos nutricionais da mandioca demonstram que ela e seus derivados possuem quantidades baixas de minerais e vitaminas (Montagnac et al. 2009), sobretudo após o processamento, pois algumas vitaminas e minerais ao serem aquecidos desintegramse. Entre a maioria dos povos indígenas da Amazônia, o processamento da mandioca é permeado por um profundo conhecimento acerca da espécie, das técnicas aplicadas, dos objetos utilizados, gerando uma diversidade de alimentos.

Nesse sentido, questiono como a mandioca pode ser considerada um alimento pobre se desde a sua domesticação estimada entre 5.000 a 7.000 anos A.C. - no sudoeste amazônico (Olsen \& Schaal, 1999; Allem, 2002; Pereira, 2011), ela é considerada por diferentes cosmologias indígenas como a planta da vida, que nutre e alimenta os povos da Amazônia. Sendo pobre, como esse alimento sustentou populações com grande e média densidade demográfica em diferentes biomas na América por tanto tempo, dentre eles os meus ancestrais?

Nós transformamos a mandioca em nossos corpos, crescemos, aprendemos, conhecemos o mundo através da mandioca. Como aceitar uma tabela nutricional exógena que afirma ser um alimento pobre, aquele que diferentes povos de diferentes lugares da Amazônia consideram ser a planta da segurança alimentar e da vida?

Na TI Uaçá os principais alimentos derivados da mandioca ou combinados são: farinha comum, farinha de tapioca, farinha de cruera, tucupi, mingau de cará, mingau farinha com açaí, mingau de farinha com bacaba, mingau de goma, mingau de farinha com inajá, mingau de macaxeira, tacaca, chibé com água e farinha, chibé de ovo de tracajá, variedades de beiju (Figura 3): beiju guigui, beiju kasab, beiju lãpwa, beiju de goma. Outros alimentos que são ingeridos com farinha: guisados (paca, jacaré, camaleão, jacaré), caldos (peixe, tracajá, tatu, jacaré, paca, pato selvagem, camaleão, jabuti, porco, veado). Assado (peixe, casco de jabuti e tracajá, porco). 
Figura 3. Variedades de beiju de mandioca na aldeia Kumarumã.

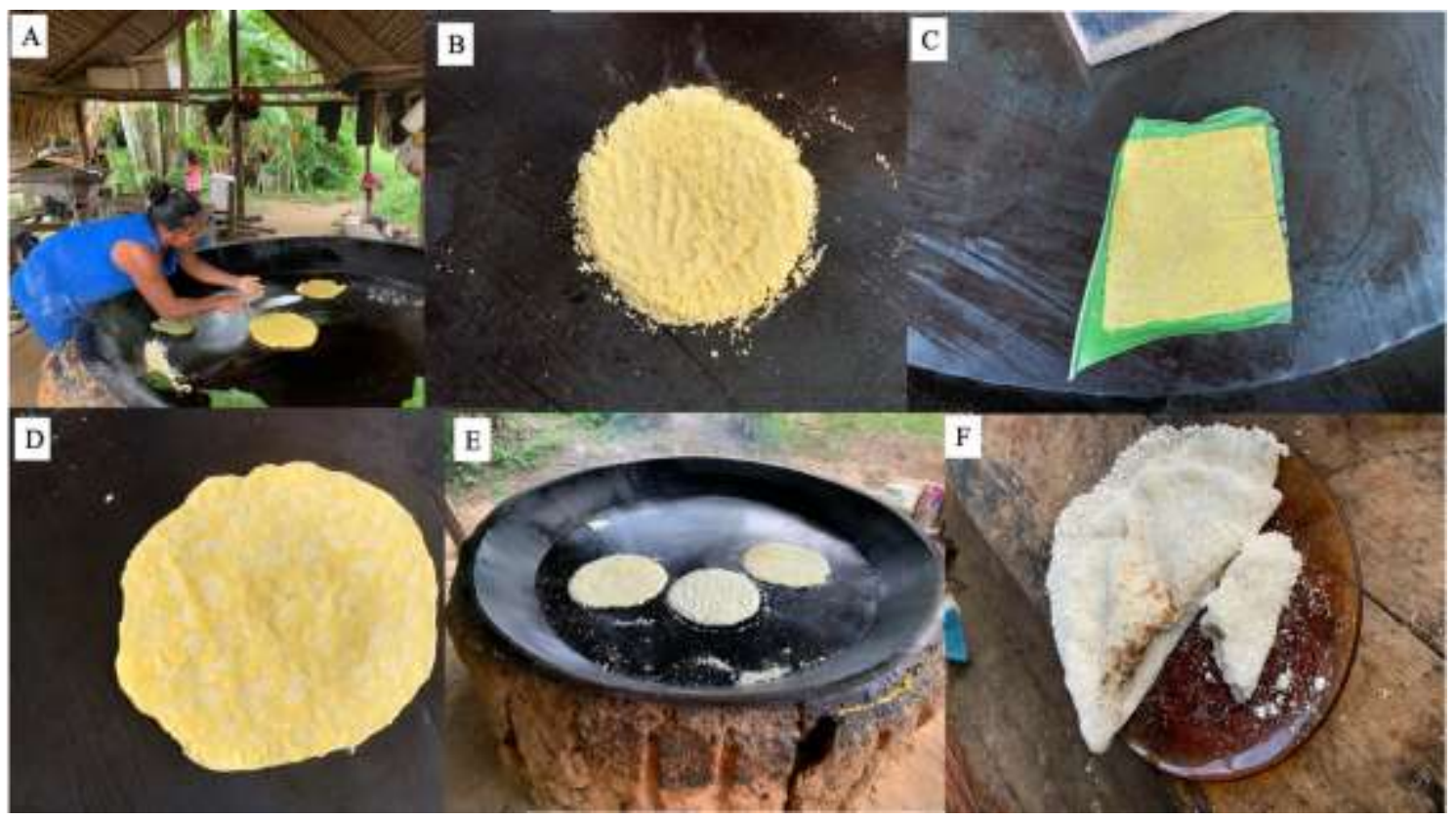

A - Indígena Galibi-marworno preparando os beijus, B e E - beiju kasab, C - beiju guigui, D - beiju lãpwa, F - beiju de goma. Fonte: Trabalho de campo (2020).

A maioria dos beijus são circulares como a Terra, neles estão expressos o conhecimento feminino - a quantidade certa de cada ingrediente, a mistura certa, o tempo de preparo, o tamanho. Cada beiju é produzido e pensado para uma refeição específica, o beiju de goma no café da manhã, o beiju kasab e o beiju guigui para comer com caldos, peixe e carnes de caças assadas, o beiju lãpwa para uma refeição rápida, como lanche. A mandioca está na base alimentar dos povos indígenas do Oiapoque e também contribui para sua segurança e soberania alimentar.

Para os povos do Baixo Oiapoque, se existe roça com variedades de manivas, tem farinha, e se tem farinha significa que todos estão seguros. Um aspecto interessante dessa segurança conferida pela planta é expresso no que testemunhei no Baixo Oiapoque, com respeito a ideia difundida entre os Galibi-Marworno e os Karipuna de que a autonomia de um homem ou grupo familiar está no fato de serem donos de sua própria roça.

Conjuntamente, mas em menor proporção, os alimentos industrializados fazem parte da dieta dos povos indígenas da TI Uaçá, que são adquiridos em maior parte na cidade do Oiapoque, quando as famílias se deslocam até a cidade para vender a farinha de mandioca, receber aposentadoria, bolsa família ou salário, no caso dos funcionários públicos, sobretudo os professores indígenas. Os comércios nas aldeias funcionam nas próprias residências.

Os alimentos industrializados, ou da "cidade" como se referem, mais consumidos nas aldeias são: arroz, frango, macarrão, óleo de soja, café, açúcar, calabresa, mortadela, salsicha, enlatados (sardinha, carne em conserva, salsicha), margarina, charque, feijão, suco em pó, farinha de trigo, pão, bolachas cream cracker, biscoitos doces, salgadinhos de milho, leite em pó, refrigerantes, carne bovina, sal, ovo, condimentos (pimenta do reino, colorau, cominho). Em relação ao pão, um fato interessante é o hábito de consumir baguette, um pão francês alongado e crocante, provavelmente herança dos intensos intercâmbios culturais na fronteira com a Guiana Francesa. A baguette é produzida em padarias caseiras, principalmente, nas aldeias maiores como Kumenê e Kumarumã, duas vezes ao dia - manhã e tarde.

Constatei em campo, através de observações participativas e convívio na TI Uaçá, que apesar do consumo de alimentos industrializados, as práticas alimentares são fortemente ancoradas na cultura indígena local, os alimentos 
tradicionais ${ }^{7}$ são os mais consumidos e preferidos pela maioria, ao contrário do que eu postulava no início da pesquisa. Assim como Eloy (2009) concluiu em seu estudo na região do Alto Rio Negro, que a incorporação de elementos da "comida de branco" nas refeições das famílias indígenas, não significa necessariamente uma ruptura com o modelo alimentar tradicional, pode-se apontar alguma analogia com o Baixo Oiapoque.

Porém, há uma preocupação em relação ao aumento do consumo dos industrializados, sendo perceptível uma crescente transição alimentar, principalmente entre as crianças e os jovens que inclui vários fatores, entre eles a merenda escolar que é fornecida nas escolas indígenas não é regionalizada, ou seja, fornecem alimentos altamente calóricos, processados e enlatados. Por outro lado, já se observa os impactos negativos desses alimentos na saúde indígena, pois pessoas de diferentes faixas etárias falam sobre doenças que antigamente não existiam nas aldeias e são decorrentes da entrada dos alimentos industrializados.

Nesse sentido, a transição alimentar percebida também alimenta um discurso de que é necessário dar mais importância aos alimentos tradicionais e resgatar alguns hábitos antigos, como tomar mingaus a base de derivados da mandioca (goma, tapioca, farinha) e frutas pela manhã. $\mathrm{O}$ café adoçado, o leite e pão com margarina pela manhã parecem estar bem incorporados a rotina das aldeias maiores. De fato, há uma preocupação com esses novos hábitos, conforme descrevem as pesquisadoras indígenas Felício e Orlando da etnia Palikur:

Nós ainda não temos o conhecimento do que tem dentro dos alimentos industrializados, se esses alimentos são saudáveis ou não, antes não tínhamos a preocupação de cuidar da nossa alimentação, porque era tudo natural, agora com os alimentos industrializados temos que nos preocupar. Nós já ouvimos muitos os velhos reclamar, porque os jovens hoje em dia estão tendo muitos problemas de saúde, uns têm dor de cabeça, mal-estar, tonteira, pressão alta, falta de ar. Antigamente as pessoas viviam mais e não tinha essas doenças, hoje em dia tem muitos jovens com problemas de saúde (Felício \& Orlando, 2016, p.11).

No Brasil, os discursos científicos e institucionais sobre a saúde indígena têm alertado sobre o rápido incremento de doenças crônicas associadas ao crescente consumo de alimentos industrializados (Garnelo \& Welsh, 2009), mesmo nas aldeias mais distantes. É possível que o aumento das doenças crônicas como diabetes e hipertensão na TI Uaçá estejam ligadas ao crescente processo de transição alimentar, no entanto há necessidade de aprofundamento e um estudo mais detalhado.

O que se pode afirmar, a partir das observações em campo, é que nem todo alimento industrializado impacta negativamente a saúde dos povos indígenas locais, pois alguns ajudam a incorporar na dieta outros nutrientes, como exemplo o feijão e o arroz, ou que garantem a segurança alimentar no período de escassez de peixes e caças, quando intensificam as chuvas, em abril e maio. Constato que os alimentos tradicionais e industrializados estão entrelaçados e se complementam nas aldeias que visitei.

\section{Considerações Finais}

Os povos indígenas Galibi-Marworno, Karipuna e Palikur-Arukwayene conseguem viver dentro da Terra Indígena Uaçá com as condições que ela lhes oferece, cultivando e manejando uma alta diversidade de espécies animais e vegetais, lançando mão de distintas práticas, distintos conhecimentos, em contínua transformação, um eterno recomeço de vida. Conforme Diegues (2008), esse sistema revela a existência de um complexo de conhecimentos adquiridos pela tradição herdada dos mais velhos, de mitos e símbolos que levam à manutenção e ao uso sustentado dos ecossistemas.

É importante salientar que há uma complexidade de seres - humanos e não humanos - envolvidos nas práticas de obtenção e preparo de alimentos na TI Uaçá - constelações, chuvas, sol, lua, animais domésticos e silvestres, plantas, pessoas.

\footnotetext{
${ }^{7}$ Os povos indígenas do Uaçá consideram alimento tradicional todo alimento proveniente dos cultivos locais, da caça, da pesca, da coleta, com técnicas ancestrais de preparo, armazenamento e consumo.
} 
Apesar de haver uma reciprocidade entre esses seres, as relações nem sempre são harmoniosas, em virtude da tensão entre os "donos" dos recursos alimentares, que são os seres invisíveis (karuanas), em que a primazia é o forte respeito a esses donos, antes de caçar, pescar, derrubar uma árvore, coletar uma fruta, ou abrir uma roça, traduz-se no ato de ter de pedir licença aos donos, usando somente o necessário a reprodução da vida, visto que as entidades são ciumentas dos recursos e eventualmente punem quem não caça, planta ou coleta de acordo com uma etiqueta que poderíamos chamar de sustentável, porque não admite predação excessiva.

Nós, os povos indígenas em movimento cuidamos do mundo físico com a ajuda dos seres invisíveis, os "donos" karuanas e de qualquer desobediência a etiqueta acordada com eles, espera-se uma reação negativa e por vezes perigosa, onde as plantas morrem, as pessoas adoecem, os animais somem, as tempestades e os raios aumentam, o calendário de cheia e vazão dos rios se modifica comprometendo a segurança e soberania alimentar no nosso território.

Cumpre dizer que a pandemia do COVID 19 apresentou-se na TI Uaçá como um divisor de águas, causando muita apreensão e alertando para a importância da proteção do território, de suas roças, matas, rios e campos alagados que, estando saudáveis, são garantia de sustentação do modo de seus povos mesmo em situação de pandemia, pois devido ao isolamento imposto pelas autoridades sanitárias muitos não conseguiram realizar a costumeira compra de alimentos industrializados por vários meses, recebendo cestas básicas como mitigação. Isso fez com que os alimentos locais fossem ainda mais valorizados não somente por serem alimentos considerados fortes, mas também por se consolidarem como mingaus, proteína de origem animal e frutas nativas que resguardam a continuidade da vida em situações de emergência sanitária.

É fato que os conhecimentos indígenas sobre o uso e manutenção dos ecossistemas amazônicos garantem a segurança alimentar, a soberania alimentar e o modo de vida próprio, contrapondo-se aos modos de produção e apropriação que além de destruírem os recursos naturais, fragilizam os projetos de vida e autonomia indígena. No entanto, a soberania alimentar indígena não tem a proteção do estado brasileiro, à medida que há incentivos para implantação de grandes empreendimentos dentro e no entorno das terras indígenas, além do fortalecimento do agronegócio que tem como matriz a produção de commodities e combustível.

Por fim, é necessário um esforço da ciência ocidental no sentido de compreender que nós povos indígenas também fazemos ciência, temos conhecimentos consolidados, que não são apenas mitos, e podemos contribuir e pensar uma Amazônia mais sustentável. Na TI Uaçá precisamos aprofundar a pesquisa, de forma participativa, em que medida os alimentos industrializados estão impactando negativamente no modo de vida local.

\section{Agradecimentos}

Aos povos indígenas da TI Uaçá pelo acolhimento e gentileza; à Coordenação de Aperfeiçoamento de Pessoal de Nível Superior - CAPES, pela concessão da bolsa de Doutorado; à Fundação de Amparo à Pesquisa do Amazonas - FAPEAM, pela concessão de diárias de campo; ao Instituto de Pesquisa e Formação Indígena - Iepé, pelo apoio na pesquisa e fortalecimento da autonomia indígena na TI Uaçá; ao Professor Ramiro Esdras Batista pela leitura e sugestões de melhorias no texto; ao Fabiano Maisonnave pela colaboração nas traduções.

\section{Referências}

Adams, C., Murrieta, R. S. \& Sanchez, R. A. (2005). Agricultura e Alimentação em Populações Ribeirinhas das Várzeas do Amazonas: Novas Perspectivas. Ambiente \& Sociedade. 8 (1), 1-23.

Allem, A. C. (2002). The origins and taxonomy of cassava. In: Hillocks, R .J., Thresh, J. M., Bellotti, A. C. (Eds). Cassava: biology, production and utilization. CAB International, 1-16. http://ciat-library.ciat.cgiar.org/Articulos_CIAT/cabi_04ch1.pdf.

Altieri, M. A. \& Nicholls, C. I. (2016). Agroecología y Soberanía Alimentaria en América Latina. In: Bezerra, I. \& Perez-Cassarino, J. (Orgs.) Soberania Alimentar (SOBAL) e Segurança Alimentar e Nutricional (SAN) na América Latina e Caribe. Paraná: Editora UFPR. 
https://www.researchgate.net/publication/322643794_Soberania_Alimentar_SOBAL_e_Seguranca_Alimentar_e_Nutricional_SAN_na_America_Latina_e_Ca ribe.

Associação dos povos indígenas do Oiapoque. (2009). Plano de vida dos índios e organizações indígenas do Oiapoque. Oiapoque: APIO, 45p.

Bardin, L. (2006). Análise de conteúdo. Rego, L. de A. \& Pinheiro, A. Edições 70.

Barros, L. P., Mazurek, R. R. de S., Balieiro, C. P. P., Amora, P. B. C. \& Sztutman, M. (2013). Etnomapeamento como instrumento de apoio à classificação da tipologia florestal nas Terras indígenas Uaçá, Juminã e Galibi, no estado do Amapá. In: Anais XVI Simpósio Brasileiro de Sensoriamento Remoto - SBRS, Foz do Iguaçu, PR, Brasil, p. 3191-3198.

Batista, R. E. C. (2020). Keka-Imawrí: narrativas e códigos da Guerra do fim do mundo. CMFL, Folheando, 252 p.

Becker, B. K. (2005). Amazônia: Desenvolvimento e Soberania. In: Brasil: o estado de uma nação. Instituto de Pesquisa Aplicada (IPEA). https://www.repositorio.ipea.gov.br.

Burity, V., Franceschini, T., Valente, F., Recine, E., Leão, M. \& Carvalho, M. de F. (2010). Direito Humano à Alimentação Adequada no Contexto da Segurança Alimentar e Nutricional. ABRANDH, 204p.

Chernela, J. M. (1989). Managing Rivers of Hunger: The Tukano of Brazil. In: Advances in Economic Botany, 7, 238-248, 1989. https://www.jstor.org/stable/43927555.

Dácio, A. I. C. (2017). Segurança Alimentar e Conservação nos Agroecossistemas no Alto Solimões. 163p. Tese de Doutorado, Programa de Pós Graduação em Ciências do Ambiente e Sustentabilidade na Amazônia, Universidade Federal do Amazonas, Manaus, Amazonas.

Diegues, A. C. (2008). O mito moderno da natureza intocada. São Paulo: NUPAUB - Núcleo de Apoio à Pesquisa sobre Populações humanas e Áreas Úmidas Brasileiras - USP/Hucitec.

Distrito Sanitário Especial Indígena do Amapá e Norte do Pará. (2019). População DSEI Amapá e norte do Pará. Oiapoque.

Dufour, D. L., Piperata, B. A., Murrieta, R. S., Wilson, W. M. \& Williams, D. D. (2016). Amazonian foods and implications for human biology. In: Annals of Human Biology, 43:4, 330-348. DOI: 10.1080/03014460.2016.1196245.

Eloy, L. (2009). Diversidade alimentar e urbanização: o papel das migraç̃oes circulares indígenas no Noroeste Amazônico. In: Anthropology of food. https://doi.org/10.4000/aof.6444.

Felício, N. B. \& Orlando, D. L. (2016). As mudanças nos hábitos alimentares do povo Palikur com a introdução dos alimentos industrializados na Aldeia Kumenê. 44p.Trabalho de Conclusão de Curso de Graduação, Licenciatura Intercultural Indígena, Universidade Federal do Amapá, Campus Oiapoque - AP.

Food and Agriculture Organization of The United Nations, Roma. (2004). Whats is Agrobiodiversity, 2004. https://www.fao.org/3/y5609e/y5609e01.htm\#bm1.

Food and Agriculture Organization of The United Nations, Roma. (2018). Agrobiodiversity: A training manual for farmer groups in East Africa. https://www.fao.org/3/i9307en/I9307EN.pdf .

Fraxe, T. de J. P. (2011). Homens anfíbios: etnografia de um campesinato das águas. (2a ed.), Annablume, CNPq.

Garnelo, L. \& Welsh, J. R. (2009). Transição alimentar e diversidade cultural: desafios à política de saúde indígena no Brasil. Rio de Janeiro: Cad. Saúde Pública, 25(9): 1872-1873. https://www.arca.fiocruz.br/bitstream/icict/1882/1/Editorial.pdf.

Gil, A. C. (2008). Métodos e técnicas de pesquisa social. (6a ed.), Atlas.

Grenn, L. \& Green, D. (2010). The Rain Stars, the World's River, the Horizon and the Sun's Path: Astronomy along the Rio Urucauá, Amapá, Brazil. In: Tipiti - Journal of the Society for the Anthropology of Lowland South America: 8(2), Article 3.

Gruber, K. (2017). The living library: wild and heirloom plants are giving major crop varieties, and global food system, a genetic makeover. Nature. 544, S8S10. https://www.nature.com/articles/544S8a.

Hoyos, C. J. C. \& D'agostini, A. (2017). Segurança Alimentar e Soberania Alimentar: convergências e divergências. Revista Nera. 20 (34), 174-198.

Instituto Brasileiro de Geografia e Estatística (2020). Cidades. https://cidades.ibge.gov.br/brasil/ap/oiapoque/panorama.

Instituto Chico Mendes de Conservação da Biodiversidade. (2018). Atlas dos Manguezais do Brasil. Brasília:DF. https://www.icmbio.gov.br/portal/images/stories/manguezais/atlas_dos_manguezais_do_brasil.pdf.

Instituto de Pesquisa e Formação Indígena. (2009). Turé dos povos indígenas do Oiapoque. Andrade, U.M. (org.). Rio de Janeiro, São Paulo: Museu do Índio, Iepé.

Instituto Socioambiental. (2020). Ciclos anuais dos povos indígenas do Rio Tiquié. São Paulo: SP. https://ciclostiquie.socioambiental.org/pt/index.html. Itamaraty (2020). Primeira Comissão Brasileira Demarcadora de Limites. http://pcdl.itamaraty.gov.br/pt-br/.

Johansen, A., Ronnet, T., Bizzarro, M., Schiller, M., Lambrechts, M., Nordlund, A., \& Lammer, H. (2021). A pebble accretion model for the formation of the terrestrial planets in the solar system. In: Science Advances: 7(8). 10.1126/sciadv.abc0444.

Labontê, G. dos S. (2018). Pewru-Ahavwukune: a incorporação do Canis familiaris na sociedade Palikur-Arukwayene. Trabalho de Conclusão de Curso de Graduação, Licenciatura Intercultural Indígena, Universidade Federal do Amapá, Campus Oiapoque - AP. 
Leite, M. S. (2007a). Sociodiversidade, Alimentação e nutrição Indígena. In: Barros, D. C., Silva, D. O. \& Gugelmin, S. Â. (orgs.) Vigilancia alimentar e nutricional para a saúde Indígena. Rio de Janeiro: editora Fiocruz, Cap 7, 181-210.

Leite, M. S. (2007b). Transformação e Persistência: antropologia da alimentação e nutrição em uma sociedade indígena amazônica. Rio de Janeiro: editora Fiocruz, 239p.

Maluf, R. S. (2011). Segurança Alimentar e Nutricional. Vozes, 174p.

Montagnac, J. A., Davis, C. R. \& Tanumihardjo, S. A. (2009). Nutritional value of cassava for use as a staple food and recent advances for improvement. Compr Rev Food Sci. 8:181-194.

Morin, E. Ciência com consciência. (2a ed.), Bertrand Brasil, 1998.

Morin, E. O método 1. A natureza da Natureza. Trad. Ilana Heineberg, Sulina 2013, 3.ed.

Murrieta. R. S., Bakri, M. S., Adams, C., Oliveira, P. S. de S. \& Strumpf, R. (2008). Consumo alimentar e ecologia de populações ribeirinhas em dois ecossistemas amazônicos: um estudo comparativo. Rev. Nutr., Campinas. 21(Suplemento):123s-133s.

Musolino, A. A. N. (2006). Migração, identidade e cidadania Palikur na fronteira do Oiapoque e litoral sudeste da Guiana Francesa. 187p.Tese de Doutorado, Centro de Pesquisa e Pós-Graduação sobre as Américas - CEPPAC, Universidade de Brasília, DF.

Noda, S. N., Noda, H. \& Silva, A. I. C. da. (2013). Socioeconomia das unidades de agricultura familiar no Alto Solimões: formas de produção e governança ambiental. In: Noda, H., Noda, S. N., Laques, A. E. \& Lena, P. (Orgs.) Dinâmicas socioambientais na agricultura familiar na Amazônia. Manaus: Wega, 1ed., $1,53-74$.

Nunes, E. M. (2016). A Contagem do tempo dos Galibi-Marworno na Aldeia Kumarumã. 25p. Trabalho de Conclusão de Curso de Graduação, Licenciatura Intercultural Indígena, Universidade Federal do Amapá, Campus Oiapoque - AP.

Oliveira, J. C. de. (2006). Classificações em cena: algumas formas de classificação das plantas cultivadas pelos Wajãpi do Amapari (AP). 273p. Dissertação de Mestrado, Faculdade de Filosofia, Letras e Ciências Humanas, Universidade de São Paulo, Departamento de Antropologia - SP.

Oliveira filho, K. de S. \& Saraiva, M. de F. O. (2004). Astronomia e astrofísica, (2a ed.), Livraria da Física.

Olsen, K. M. \& Schaal, B. A. (1999). Evidence on the origin of Cassava: Phylogeography of Manihot esculenta. Proceedings of the National Academy of Sciences of the United States of America, 96: 5586-5591. https://www.pnas.org/content/pnas/96/10/5586.full.pdf.

Oviedo, A., Araújo, E. N. O., Batista, J. de P. \& Santos, T. M. dos. (2020). Relatório Técnico sobre o risco iminente de contaminação de populações indígenas pelo novo coronavírus em razão da ação de invasores ilegais, ISA. https://acervo.socioambiental.org/sites/default/files/documents/prov96.pdf.

Pereira, A. A. (2011). Dinâmica evolutiva de mandioca (Manihot esculenta Crantz) em três tipos de solo manejados por caboclos na Região do Médio rio Madeira, Amazonas. 89 p. Dissertação (Mestrado em Genética, Conservação e Biologia Evolutiva) - Instituto Nacional de Pesquisas na Amazônia, INPA, Manaus - AM.

Pesquisadores indígenas do museu kuahí, Laval, P. \& Vidal, L. (2018). Peixes e pesca: Conhecimentos e Práticas entre os Povos Indígenas do Baixo Oiapoque, Amapá. Iepé.

Posey, D. A. (1986). Introdução. In: D. Ribeiro (ed.). Suma etnológica brasileira. Vol 1: Etnobiologia (Coord. B.G.Ribeiro). Editora Vozes, Finep.

Salgado, C. A. B. (2007). Segurança alimentar e nutricional em terras indígenas. Revista de Estudos e Pesquisas, FUNAI. 4(1), 131-186. http://cpu007782.ba.gov.br/sites/default/files/biblioteca/direitos-humanos/populacao-indigena/artigos_teses_dissertacoes/04-carlos_antonio_bezerra_salgadoseguranca_alimentar_e_nutricional_em_terras_indigenas.pdf.

Santos, D. F. dos. (2015). Núcleo Museológico Virtual da Aldeia Kumarumã: Instrumento de Resistencia Sócio-Cultural. 57p.Trabalho de Conclusão de Curso de Graduação, Licenciatura Intercultural Indígena, Universidade Federal do Amapá.

Santos, R. V., Coimbra jr., C. E.A. \& Cardoso, A. M. (2007). Povos indígenas no Brasil. In: Barros, D. C., Silva, D. O. \& Gugelmin, S. A. (orgs.) Vigilância alimentar e nutricional para a saúde Indígena. editora Fiocruz, Cap 1, 23-45.

Silva, C. A. da (2020). Sustentabilidade na Amazônia Pré-colombiana. Canal science talk no youtube. https://www.youtube.com/watch?v=eb_scpdc6mq.

Schroeder, H. et al. (2017). Origins and genetics legacies of the Caribbean Taino. PNAS Latest Articles, 1-6. https://www.pnas.org/cgi/doi/10.1073/pnas1716839115.

Silva, M. A. da. (2020). Galibi Marworno, Palikur, Galibi Kaliña E Karipuna: Demarcando Territórios e territorializações - Oiapoque/AP - Amazônia. 420p.Tese de Doutorado, Faculdade de Ciências e Letras, Universidade Estadual Paulista "Júlio de Mesquita Filho", Campus Araraquara - SP.

Suremain, C. E. de \& Katz, E. Introdução: Modelos alimentares e recomposições sociais na América Latina. 2009. Anthropology of food. https:// https://doi.org/10.4000/aof.6433.

The Language Archive (2019). Elan. https://tla.mpi.nl/tools/tla- tools/elan/.

Toledo, V. M. (1992). What is ethnoecology? Origins, scope and implications of a rising discipline. Etnoecológica 1 (1): 5-21.

Valente, F., González, J. C. M., Franceschini, T. \& Burity, V. (2016). Direito Humano à Alimentação e Nutrição adequadas. In: Bezerra, I. \& Perez-Cassarino, J. (Orgs.) Soberania Alimentar (SOBAL) e Segurança Alimentar e Nutricional (SAN) na América Latina e Caribe. Paraná: Editora UFPR, 2016. https://www.researchgate.net/publication/322643794_Soberania_Alimentar_SOBAL_e_Seguranca_Alimentar_e_Nutricional_SAN_na_America_Latina_e_Ca ribe. 
Research, Society and Development, v. 10, n. 5, e7310514465, 2021

(CC BY 4.0) | ISSN 2525-3409 | DOI: http://dx.doi.org/10.33448/rsd-v10i5.14465

Viveiros de castro, E. (2002). Imagens da natureza e da cultura. In: A Inconstância da Alma Selvagem. Casc \& Naify, 317-344.

Yin, R. K. (2015). Estudo de caso: planejamento e métodos. (5a ed.), Bookman. 